\title{
VOCÊ É O QUE VOCÊ VESTE: relações simbólicas entre produtos de moda e identidades
}

\author{
Me. Mariana Toledo Seferin \\ Centro Universitário Unilasalle \\ marianaseferin@gmail.com \\ Dr. Júlio Carlos de Souza van der Linden \\ Universidade Federal do Rio Grande do Sul \\ julio.linden@ufrgs.br
}

Resumo: Este artigo aborda o relacionamento entre produtos de moda e a expressão de identidade sob o enfoque da semiótica procurando desvendar suas possíveis significações. Por meio de uma revisão de literatura é investigado como o vestuário e os acessórios de uso pessoal afetam, influenciam e afirmam nossa identidade; a necessidade das pessoas em manter uma relação emocional e subjetiva com seus objetos de uso pessoal que são utilizados como instrumentos de expressão de sua individualidade. Em um contexto sociológico definições de identidade e autoidentidade são abordadas e relacionadas. A moda, vista como fenômeno de exposição da identidade influenciando o estilo pessoal de indivíduos.

Palavras-chave: moda, identidade, semiótica e status social.

\begin{abstract}
This article discusses the relationship between fashion products and identity expression from the semiotics perspective seeking to unveil its possible meanings. Through a literature review is investigated how clothing and accessories for personal use can affect, influence and assert our identity; the people's necessity to maintain an emotional and subjective relationship with their personal belongings which are used as instruments of expression of their individuality. In a sociological context definitions of identity and self-identity are discussed and related. Fashion, seen as phenomenon of identity exposure, influencing individuals personal style.
\end{abstract}

Keywords: fashion, identity, semiotics and social status. 


\section{INTRODUÇÃO}

Este artigo tem como objetivo abordar o relacionamento entre produtos de moda e identidades dentro da perspectiva do simbolismo e da semiótica. O vestuário é capaz de tornar visível nossa identidade para o mundo afora, isso é possível devido ao simbolismo incutido em nossas vestes.

Atualmente vêm crescendo o interesse em pesquisas sobre a aparência, devido à relação entre o bem-estar individual e da formação identitária. "A moda vestimentar é um dos principais produtos de troca e de investimentos simbólicos da contemporaneidade." Ela possibilita a interação entre indivíduos e grupos sociais, uma vez que facilita a identificação de semelhantes (Oliveira, 2002).

A roupa segundo Giddens é "um meio de exibição simbólica, um modo de dar forma exterior às narrativas da autoidentidade", como também "é um meio de auto exibição, (...) se relaciona diretamente à ocultação/revelação a respeito das biografias pessoais - liga as convenções a aspectos básicos da identidade".

Designers devem ter uma autopercepção sobre o que as pessoas fazem com os produtos (Krippendorff, 2006). Para haver o design centrado no usuário é necessário compreender os significados atribuídos aos objetos pelas pessoas. Com frequência o significado mostra-se mais importante do que a função prática, isso é bem evidente nos artigos de vestuário. Um bom exemplo disso:

Considere as senhoras de sapatos de salto alto. Dizem que eles tornam-as elegantes, fazem as pernas de uma mulher parecerem mais longas, e a usuária fica parecendo ser vários centímetros mais alta, todos esses são atributos semânticos que o uso de tais calçados incentiva. $O$ fato de que eles são ergonomicamente inadequados para caminhar distâncias normais e até mesmo no longo prazo danoso para os pés da usuária, aparentemente não servem como argumentos para colocar um ponto final à sua produção em massa ou desencorajar o uso generalizado. Quando uma mulher chega em casa de uma ocasião formal, a primeira coisa que ela troca são os sapatos desconfortáveis que ela usava, essencialmente para definir a si mesma para os outros (Krippendorff, 2006, p.49).

O presente artigo estrutura-se do seguinte modo, num primeiro momento é abordado o surgimento da moda altamente relacionado a simbolismos que geravam o status social ao usuário dos produtos em moda. Em seguida a busca por identidade é relacionada ao uso de produtos. E finalmente sob o enfoque semiótico a expressão da identidade é relacionada ao simbolismo incutido no vestuário de moda. Uma breve apresentação do tema, dos objetivos, noções do referencial teórico, da metodologia e alguns pontos marcantes do trabalho.

\section{MODA, SIMBOLISMO E STATUS SOCIAL}

O vestuário foi inicialmente desenvolvido com a intenção de proteção do corpo humano das intempéries do clima. Mas desde as primeiras civilizações o vestuário expressou a cultura, os ideais e o status das sociedades que o criaram (Walford, 2007). A moda sempre foi conectada com a expressão de status social pessoal, facilmente se percebe isso analisando a história ocidental. $\mathrm{Na}$ antiga sociedade de classes, as pessoas componentes do clero, da nobreza e o povo (camponeses e burgueses) procuravam distinguir suas diferentes classes sociais por meio do uso de símbolos que expressassem status. Esses poderiam ser formas de comportamento, de linguagem, uso de objetos e principalmente por meio de vestimentas (Lobach, 2001). Cores, 
estilos e materiais possuíam significados simbólicos determinantes na afirmação de maior ou menor status. O uso ou não uso de certos produtos não eram meras convenções, durante a idade média imperavam leis sobre o que poderia ser vestido para determinada classe social. A moda era um privilégio das classes mais altas. A hierarquia social limitava o uso de determinados modelos de roupas e acessórios para o clero, para a nobreza e para os plebeus. Em determinado momento o custo de materiais para a confecção de produtos de vestuário se tornou mais acessível e para assegurar o uso desses itens foram criadas leis suntuárias que determinavam o que cada classe poderia vestir (Walford, 2007).

A partir do século XVII as leis suntuárias que continuavam a existir passaram a exercer menor força, pois as economias internas precisavam ser mantidas, dessa forma a distinção de moda entre classes sociais começou a deixar de existir e a "moda passou a ser uma mercadoria que foi comercializada em toda a Europa, permanecendo elitista através do consumo, qualidade e extravagância" (Walford, 2007). Qualquer um poderia estar na moda se tivesse como adquirir os produtos. Foi nesse momento que a classe trabalhadora passou a utilizar tendências de moda adaptando-as ao seu bolso, substituindo materiais caros por materiais de valor mais acessível. A partir desse século a moda popularizou-se (ou seja, não era mais restrita a determinadas classes sociais) e a distinção no vestuário passou a ser vista na escolha de materiais. Qualquer um poderia estar na moda se tivesse como adquirir os produtos. Foi nesse momento que a classe trabalhadora passou a utilizar tendências de moda adaptando-as ao seu bolso, substituíndo materiais caros por materiais simplórios.

O filósofo Lars Svendsen escreveu que Adam Smith, Kant e Spencer compartilham a mesma visão sobre o surgimento da moda, que segundo eles teve origem na imitação do vestuário da nobreza pelo povo. As classes inferiores sempre procuraram elevar seu status social pelo uso do vestuário "em moda" e sua simbologia intrínseca contida nele. O uso de símbolos por meio do vestuário é um indicador da identidade de um indivíduo (Svendsen, 2010). Segundo Simmel (2008) e Svendsen (2010) existe um vínculo entre a moda e a identidade. O vestuário faz parte do indivíduo, ele não é algo externo à nossa identidade pessoal (Svendsen, 2010). "O vestuário é parte do indivíduo, não algo externo à identidade pessoal" (Svendsen, 2010). Danesi (1999) afirma que as "roupas transferem personalidade (identidade, gênero, idade, status) e regulam a interação social".

Para Woodward $(2007$, p.29) as considerações implicadas na escolha do que vestir pelas mulheres variam entre os papéis sociais assumidos por elas, sua feminilidade, a moda, sua identidade pessoal, seus relacionamentos interpessoais e sua família. De acordo com Solomon, "muitos significados de produtos derivam de sua associação com papéis sociais" (Solomon apud Kälviäinen, 2002). O status é adquirido através do simbolismo presente nos produtos. Para Kälviäinen (2002) as pessoas utilizam produtos/objetos, que contenham um simbolismo adequado, para compensar a falta de alguma característica que em suas concepções deveriam possuir, assim uma pessoa que deseja ser poderosa poderá vir a utilizar itens que enalteçam poder, como por exemplo: um sapato de salto alto ou uma gravata.

Símbolos são centrais para toda conformação de identidade (Svendsen, 2010), eles são usados para dar significado e assim dizer algo a respeito de quem os usa. Não somente nas sociedades do passado como ainda hoje eles servem para comunicar a nossa identidade pessoal, bem como a nossa identidade social, a diferença é que hoje 
os símbolos muitas vezes possuem significados transitórios, que serão determinados pelas tendências da moda atual, assim o que antes era moda, poderá passar a ser ultrapassado e esse no futuro poderá se tornar moda novamente. Produtos são relacionados com estereótipos e são os seus estilos que darão a possibilidade de identificá-los. Assim, gostos e preferências serão formados a partir da escolha de seu grupo de referência. E o uso desses produtos serão mediadores da interação social entre o usuário e sua rede social (Kälviäinen, 2002).

O setor da moda é visto como um gosto coletivo, uma preferência universal que será retratada pela tendência atual. A moda muda semestralmente alterando esse gosto coletivo, "é um fenômeno sociológico (...) que passa pelas seguintes fases: lançamento, aceitação, cópia e desgaste" (Treptow, 2007). Segundo Baxter, a indústria da moda é modificada semestralmente baseada na tendência social do estilo que procura massificar cores, feitios, acessórios etc (Baxter, 2008). As pessoas utilizam a moda como um meio de expressão, e com o auxílio da simbologia dela demonstram mesmo que inconscientemente o grupo de que fazem parte. $O$ uso da moda auxilia a procura por uma identificação própria, como também ajuda as pessoas a sentirem-se socialmente aceitas nos grupos sociais a que pertencem (Lazzarotto, 2010). Simmel (2008) argumenta que a moda é capaz de compensar a "insignificância da pessoa, a sua incapacidade de, só por si mesma, individualizar a existência, através da incorporação num círculo caracterizado justamente pela moda, que por ela sobressai e de algum modo se coaduna para a consciência pública".

Conforme Godart (2010), "a moda é um fato social total, visto que além de ser simultaneamente artística, econômica, política, sociológica, ela atinge questões de expressão da identidade social". Para ele a constituição do significado na indústria da moda é de importância central, seja o significado dos estilos ou das identidades pessoais ou sociais.

Artefatos possuem um tipo de 'poder' cultural, influenciando imperceptivelmente nosso comportamento e atitudes. Para Crane (2006), "As roupas como artefatos, 'criam' comportamentos por sua capacidade de impor identidades sociais e permitir que as pessoas afirmem identidades sociais latentes". Dessa forma, as pessoas utilizam os significados dos objetos para construir sua imagem social, tanto para se afirmar para si mesmas como para os outros.

As pessoas demostram ser adeptas de grupos ou práticas pela manifestação de sinais identitários, onde o vestuário se configura como parte essencial, mas não singular, uma vez que a cultura, hábitos, objetos, gostos e sotaques também exaltam sinais identitários (Godart, 2010). Por meio desses sinais, as pessoas se reconhecem como afins com outras. É claro que nem todos os sinais são perceptíveis visualmente. Godart (2010) afirma que é com a observação desses sinais identitários que a indústria da moda desenvolve "seus fenômenos fundamentais de imitação e diferenciação". Onde o vestuário poderia ser utilizado como um modo de imitação dos outros (identidade social) ou de diferenciação das outras pessoas (identidade pessoal). Da mesma maneira que a moda é utilizada para unir pessoas de gostos afins através da imitação, é também usada para a expressão pessoal por meio da diferenciação. Para Simmel (2008) a imitação é fascinante para as pessoas pelo fato de ela livrar "o indivíduo da dor da escolha e deixa-o, sem mais, aparecer como um produto do grupo, como um receptáculo de conteúdos sociais". 
Pode-se comparar esse fenômeno de imitação e diferenciação da moda como o que Csikszentmihalyi e Rochberg-Halton (1999) chamam de integração $e$ diferenciação. Para eles "as coisas podem servir como meio de diferenciação individual" (Csikszentmihalyi; Rochberg-Halton, 1999), destacando aspectos individuais da personalidade do indivíduo, versando a sua singularidade pessoal. A integração diz respeito à identidade social, sobre o poder dos objetos em expor traços da personalidade, da cultura, do estilo de vida das pessoas, ajudando-as na identificação de semelhanças entre elas. Desse modo, "o objeto expressa simbolicamente a integração do possuidor com seu contexto social" (Csikszentmihalyi; Rochberg-Halton, 1999). Em outras palavras, "produtos podem se tornar símbolos de diferenciação social, integração ou status" (Krippendorff, 1989).

\section{IDENTIDADE}

Segundo Bauman (2001), "a busca da identidade é a busca incessante de deter ou tornar mais lento o fluxo, de solidificar o fluido, de dar forma ao disforme." E as identidades somente parecem ser sólidas, estáveis "quando vistas de relance, de fora", ou seja quando enxergadas pelos olhos dos outros ou do próprio indivíduo quando este a observa depois de um tempo passado. Para ele, todas ou quase todas as identidades são instáveis, podemos assumir diversas identidades ao longo de nossa vida. Ele argumenta que o ato de "ir às compras" faz possível ao indivíduo a seleção de uma nova identidade. "Todo o processo de compra, diz Pierre Martineau, é uma interação entre a personalidade do indivíduo e a do produto" (Motivation et Publicité apud Baudrillard, 2004). Nessa afirmação podemos entender essa interação como parte de um processo de analisar a compatibilidade entre a personalidade do indivíduo e a do produto, bem como podemos interpretar a personalidade do indivíduo como algo mutável e não fixo, capaz de ser influenciada pelo uso de produtos.

Possuímos liberdade para trocar, manter ou desfazer identidades de acordo com a nossa vontade. Bauman (2001) coloca em questão o quanto essa liberdade existe de fato de maneira espontânea considerando o quanto somos influenciados pela mídia no consumo de objetos produzidos em massa.

O sociólogo afirma que "(...) as coisas são os ornamentos simbólicos das identidades e as ferramentas dos esforços de identificação (...)" (Bauman, 2001). Ele cita Alfred Sloan que propôs a ideia da obsolescência planejada e que dizia que os produtos é que davam significado a vida das pessoas. Assim Bauman argumenta que:

\footnotetext{
Num mundo em que coisas deliberadamente instáveis são a matériaprima das identidades, que são necessariamente instáveis, é preciso estar constantemente em alerta; mas acima de tudo é preciso manter a própria flexibilidade e a velocidade de reajuste em relação aos padrões cambiantes do mundo "lá fora". (Bauman, 2001, p.100)
}

Para Bauman, as pessoas do século XX se questionam não tanto sobre como adquirir novas identidades, mas sim em como escolher uma identidade antes que essa seja "retirada do mercado ou despida de seu poder de sedução" (Bauman, 2009).

\section{SIMBOLISMO CONTIDO NO VESTUÁRIO E A EXPRESSÃO DA IDENTIDADE}

As motivações das pessoas perante os produtos muitas vezes "não são racionais e determinadas por critérios objetivos, mas sim simbólicas e derivadas a 
partir de uma compreensão individual" (Krippendorff, 1989). O que importa não é a função, mas sim o significado do objeto atribuído pelas pessoas. Krippendorff (2006) propõe um axioma para o desenvolvimento do design centrado nas pessoas. 0 axioma é constituído de: sentido, significado e contexto.

O sentido abrange nossos cinco sentidos: audição, visão, olfato, paladar e tato. Através do sentido percebemos o que é diferente, o que não nos é habitual. 0 sentido nos é informado de acordo nossas "disposições, necessidades, e expectativas, incluindo emoções, tudo do qual tem relação com o corpo humano" (Krippendorff, 2006).

O significado "restaura as diferenças percebidas entre o que é sentido e o que parece estar acontecendo" (Krippendorff, 2006). O significado auxilia na compreensão sobre o que é sentido, e no contexto de outros sentidos. O significado pode se manifestar em cinco diferentes maneiras: na percepção, na consciência de que algo pode ser percebido em diferentes maneiras; na leitura, na interpretação e composição de textos; na linguagem, na descrição de como os artefatos podem ser comunicados, conceitualizados; na conversa com outras pessoas, quando há consciência das divergências de opinião sobre o significado de determinado artefato; como representação, no significado das imagens fotográficas, "imagens significam o que elas podem re-presentar aos seus espectadores" (Krippendorff, 2006).

O contexto entende que o significado de um objeto só pode ser completamente interpretado dentro de um contexto. "Significados e contextos são gêmeos" (Krippendorff, 2006), mas podem agir de diferentes modos. O contexto limita a quantidade de significados.

O desenvolvimento dos significados de um símbolo é baseado em convenções culturais, "símbolos são capazes de transportar sentimentos e atitudes que possuam uma existência objetiva em situações imediatas externas, e esse desenvolvimento de autoconsciência é geralmente considerado a maior realização da humanidade" (Csikszentmihalyi; Rochberg-Halton, 1999). É através dos símbolos que comunicamos por meio de imagens, objetos, rituais e palavras, sentimentos como amor, medo e admiração, "em quase todas as culturas, objetos são escolhidos para representar o poder do portador" (Csikszentmihalyi; Rochberg-Halton, 1999). Esse poder expressa diferentes características em homens e mulheres. Nos homens esse poder está associado à expressão de virtudes viris como coragem, bravura, resistência e força. Já nas mulheres o poder é expresso por objetos que exaltam sua feminilidade, sedução e fertilidade, como por exemplo, sapatos de salto alto "que são associados com sexo, status, feminilidade e moda" (Steele, 2005).

No sistema de Moda, a cada estação do ano, o signo é formulado ou reformulado, não pelas pessoas em geral, mas sim pelos ditadores de moda, o "fashion-group". Muitas vezes tendências são observadas nas ruas, mas são apenas consolidadas como tendências de moda pela própria indústria da Moda. Dessa forma, a Moda (as tendências) "nasce brusca e integralmente, a cada ano, por decreto" (Barthes, 1979), decreto esse que é exposto nas passarelas, revistas e grifes e grandes magazines e assim espalhando-se a nível universal chegando às lojas.

Para Barthes (1979), é "na proporção de sua arbitrariedade mesmo que a Moda desenvolve toda uma retórica da Lei e do Fato, tanto mais imperativa quanto mais sem freio for a arbitrariedade que ela deve racionalizar ou naturalizar". Sendo assim a Moda pode ser vista tanto como um Legi-signo quanto como um Sin-signo. A Moda 
tendo como seu fundamento um legi-signo é vista como algo que deve ser seguido, algo decretado como uma lei, se a pessoa está fora de moda, ela é vista como inferior perante aos que estão "na moda", aqui encontramos o status social. Lembramos que a ideia da moda como lei é muito antiga, visto que ela foi justamente instituída pelas leis suntuárias da Idade Média, até mesmo no Egito Antigo já existia a diferenciação de vestuário nas classes sociais. Atualmente continuamos a sentir a Moda como lei, não somente na questão de status social, mas também, na dificuldade de encontrar produtos, roupas que não estão na moda atual. Se eu procuro uma calça pantalona e está não está na Moda, dificilmente irei encontrar alguma loja vendendo, terei de procurar em algum brechó ou terei de encontrar um meio para confeccioná-la. Até mesmo aqueles que não querem vestir a Moda atual, podem vir a ser dependentes dela por falta de alternativa. De acordo com Santaella (2002) "a ação da lei é fazer com que o singular se conforme, se amolde à sua generalidade" essa afirmação traduz muito bem a visão da Moda como um legi-signo, forçando os indivíduos a segui-la.

Já a Moda tendo como seu fundamento um fato, um sin-signo, visto que "a propriedade de existir, que dá ao que existe o poder de funcionar como signo" (Santaella, 2002). O que existe emana sinais repletos de significados. Tanto a Moda, como o vestuário transmitem sinais que estão prontos para serem interpretados e que podem possuir diversos significados.

Uma das questões que Barthes aborda em seu livro Sistema da Moda é a transitoriedade dos significados da Moda, para ele "a Moda não evolui, antes muda: seu léxico é novo, a cada ano, como o de uma língua que guardasse o mesmo sistema, mas mudasse, brusca e regularmente a 'moeda' de suas palavras". Essa afirmação remete a ideia do brega e do moderno, como o mesmo item em determinada estação pode estar "em alta" na moda e em outra é visto como obsoleto, sinal de mal gosto, cafona. Devido a essa transitoriedade de significados que se pode afirmar que definitivamente a Moda não evolui, ela gira em torno de si mesma, transformando, revivendo e anulando facilmente os significados das peças de vestuário. Aqui está presente a ideia da Moda como um jogo expressa por Barthes, para ele é nessa brincadeira de troca de significados do vestuário, que o mesmo "pega contato com a pessoa, denota uma personalidade suficientemente rica para mudar frequentemente de papel", acabando por influenciar a manifestação da identidade do indivíduo, tornando fácil a troca da identidade com a troca de roupa, de modo que "transformando o vestuário, transforma-se a alma" (Barthes, 1979).

A Moda proporciona para as pessoas a opção de identidade e de jogo pelo uso do vestuário. O sonho de identidade é manifestado pela expressão de si mesmo, seja com o uso de modismos ou não, o que importa é a manifestação do estilo pessoal do indivíduo em sua aparência. Já o jogo proporciona ao indivíduo se transformar em outro, aqui está presente a questão do disfarce. Na visão da Moda, "o vestuário não é jogo, mas signo de um jogo" (Barthes, 1979). O indivíduo se depara constantemente com a questão de ser ele mesmo ou de se transformar em quem gostaria. "A multiplicação das pessoas num único ser é sempre considerada pela Moda como um índice de poder", poder do indivíduo em ser capaz de se transformar em outro e o poder da Moda em sua capacidade de transformar o indivíduo (característica de um sin-signo indicial).

Essa escolha pela identidade e/ou pelo jogo denota características de secundidade, a começar pela relação de dualidade da escolha, que gera a sensação do 
desconforto, da dúvida de quem éramos, somos e quem queremos ser. Esses fatos externos (vestuário) atingem nossos sentidos e conectam-se a nossa percepção de quem nós somos, à nossa autoidentidade. Autoidentidade foi uma definição criada por Anthony Giddens que expressa a reflexividade do self, a identidade analisada continuamente, planejada e capaz de ser alterada conscientemente, "é o eu compreendido reflexivamente pela pessoa em termos de sua biografia" (Giddens, 2002).

\title{
5. CONSIDERAÇÕES FINAIS
}

Segundo Santaella, "signo é aquilo que dá corpo ao pensamento, às emoções, reações etc. Por isso mesmo, pensamentos, emoções e reações podem ser externalizados. Essas externalizações são traduções mais ou menos fiéis de signos internos para signos externos" (Santaella, 2002, p.10). Essa afirmação exemplifica muito bem a manifestação (externalização) da identidade pelo uso do vestuário.

Para Oliveira (2002), a moda auxilia na interação entre as pessoas, uma vez que as roupas que vestimos exprimem nossos traços identitários pela emissão de seus significados.

\begin{abstract}
Muito além de um veículo de informações entre um emissor e um receptor, a moda é um sistema de significação que promove entre os sujeitos dos dois pólos da relação, diversos tipos de relações intersubjetivas e papéis sociais, ao mesmo tempo que cria identidades e alteridades, e difunde gostos, preferências estéticas, estilos, modos de sentir e de viver. Uma vez adotados, esses entram na definição dos modos de vida que nos remetem, para avançar no seu entendimento, a abordá-la enquanto fenômeno de significação (Oliveira, 2002, p.132).
\end{abstract}

Fica uma questão a ser respondida: como expressar quem somos quando o sistema de moda é regido por tendências sazonais massificadas? Conforme Barthes (1979) o poder de significação da moda é ilimitado. A expressão da identidade por meio do vestuário é determinada pelo simbolismo incutido no mesmo, esse pode ser regido a nível social (normas sociais - Moda) ou individual (associações significativas pela memória do indivíduo).

Nossas roupas nos ajudam a nos encontrar, expressar e afirmar como indivíduos. Hoje, as necessidades dos indivíduos perante aos produtos aumentaram, "além de serem funcionais, em nível físico, e usáveis, em nível fisiológico, devem estabelecer com o destinatário uma relação em nível subjetivo, emocional ou cognitivo" (Niemeyer, 2008). Assim, como também devem ser capazes de expressar o estilo de vida, a personalidade e a identidade do indivíduo. Segundo Lucy Niemeyer, são as nossas relações com os nossos produtos que nos fazem capazes de nos reconstruir, de rever nossas leituras sobre o mundo e também de nos situarmos em frente ao mundo, assim nós mesmos nos conhecemos e nos sentimos parte de algo.

\section{REFERÊNCIAS}

BARTHES, Roland. Sistema da Moda. São Paulo: Companhia Editora Nacional (USP), 1979.

BAUDRILLARD, Jean. O sistema dos objetos. São Paulo: Perspectiva, 2004.

BAUMAN, Zygmunt. Modernidade Líquida. Rio de Janeiro: Zahar, 2001.

. A Sociedade Individualizada. Rio de Janeiro: Zahar, 2009. 
BAXTER, Mike. Projeto de produto: guia prático para o design de novos produtos. São Paulo, SP Edgard Blücher, 2003.

CRANE, Diana. A moda e seu papel social: classe, gênero e identidade das roupas. São Paulo: Editora Senac São Paulo, 2006.

CSIKSZENTMIHALYI, Mihaly and ROCHBERG-HALTON, Eugene. The meaning of things: domestic symbols and the self. Cambridge: Cambridge University Press, 1999.

DANESI, Marcel. Of Cigarettes High Heels, and other interesting things: an introduction to semiotics. New York: Palgrave Macmillan: 2008.

GIDDENS, Anthony. Modernidade e Identidade. Rio de Janeiro: Zahar, 2002.

GODART, Frédéric. A sociologia da Moda. São Paulo: Editora Senac, 2010.

KÄLVIÄINEN, Mirja. Product Design for Consumer Taste. In: GREEN, Willian S.; JORDAN, Patrick W. Pleasure with Products: beyond usability. London: Taylor \& Francis, 2002, p. 77-95.

KRIPPENDORFF, Klaus. The Semantic Turn: a new foundation for design. Boca Raton: Taylor \& Francis Group, 2006.

LAZZAROTTO, Giovana B. A busca por tendências comportamentais é uma tendência entre as empresas. In: DE CARLI, Ana Mery S.; MANFREDINI, Mercedes L. (org). Moda em Sintonia. Caxias do Sul: EDUCS, 2010.

NIEMEYER, Lucy. Design Atitudinal: uma abordagem projetual. In: MONT'ALVÃO, Claudia; DAMAZIO, Vera (org). Design, ergonomia e emoção. Rio de Janeiro: Mauad, 2008, p. 49-64.

OLIVEIRA, Ana Cláudia Mei Alves de. Por uma semiótica da moda. In: CASTILHO, Kathia; GALVÃO, Diana (org). A moda do corpo o corpo da moda. São Paulo: Ed. Esfera, 2002, p. 126-134.

SANTAELLA, Lucia. Semiótica Aplicada. São Paulo: Thomson, 2002.

SIMMEL, Georg. Filosofia da moda e outros escritos. Lisboa: Texto \& Grafia, 2008.

STEELE, Valerie. Shoes: A lexicon of style. United Kingdom: Co \& Bear Productions, 2005.

SVENDSEN, Lars. Moda: uma filosofia. Rio de Janeiro: Zahar, 2010.

TREPTOW, Doris. Inventando moda planejamento de coleção. Brusque, SC: D. Treptow, 2007.

WOODWARD, Sophie. Why women wear what they wear. Oxford: Berg, 2007. 